\title{
USE OF ADHESION PROMOTERS IN ASPHALT MIXTURES
}

\author{
Denisa CIHLÁŘOVÁ1* ${ }^{*}$, Ivan FENCL ${ }^{1}$, Silvia CÁPAYOVÁ2, Petr POSPÍŠIL ${ }^{1}$
}

\begin{abstract}
The purpose of asphalt binder as a significant binder in road constructions is to permanently bind aggregates of different compositions and grain sizes. The asphalt binder itself does not have suitable adhesiveness, so after a period of time, bare grains can appear. This results in a gradual separation of the grains from an asphalt layer and the presence of potholes in a pavement. Adhesion promoters or adhesive agents are important and proven promoters in practice. They are substances mainly based on the fatty acids of polyamides which should increase the reliability of the asphalt's binder adhesion to the aggregates, thus increasing the lifetime period of the asphalt mixture as well as its resistance to mechanical strain. The amount of a promoter or agent added to the asphalt mixture is negligible and constitutes about $0.3 \%$ of the asphalt's binder weight. Nevertheless, even this quantity significantly increases the adhesive qualities of an asphalt binder.

The article was created in cooperatation with the Slovak University of Technology, in Bratislava, Slovakia, and focuses on proving the new $A D 2$ adhesive additive and comparing it with the Addibit and Wetfix BE promoters used on aggregates from the Skuteč - Litická and Bystrec quarries.
\end{abstract}

\section{Address}

1 Faculty of Civil Engineering, VŠB - Technical University of Ostrava, Czech Republic

2 Faculty of Civil Engineering, Slovak University of Technology in Bratislava, Slovak Republic

* Corresponding author: denisa.cihlarova@vsb.cz

\section{Key words}

- Asphalt binders,

- Additives,

- Adhesion promoters,

- Adhesion assessment.

\section{INTRODUCTION}

Bitumen binder is a significant building material used both in road constructions and for other building purposes. The first references to the use of this material date back to ancient history. Increases in its use started at the beginning of the twentieth century with the rise of the petrochemical industry. Today, it is a commonly used material without which most road communications cannot be done. In the Czech Republic, $97 \%$ of the road communications contain asphalt surface wearing course. The asphalt layers of pavements comprise the upper construction of a non-solid pavement, which is directly exposed to the horizontal and tangential strain effects of vehicles. These effects are then shifted to other layers of the road construction. The top surface dressing (the abrasive/surface course) layer is directly exposed to atmospheric and climatic influences. The pavement surface dressing should therefore be impermeable, even, and have adequate anti-slip qualities throughout its lifetime so that safe, fast and comfortable ride is ensured. In order to meet these requirements, it is not only necessary to provide a suitable construction material (Stehlik at. al., 2015), (Komacka at. al., 2014), (Wu at. al, 2015), but also to maintain the construction technology; otherwise, various defects such as an adhesion failure among the individual asphalt layers (Hamzah at. al., 2014) or unsuitable surface properties on the abrasion layers may occur.

\section{ADHESION OF ASPHALT BINDERS}

When a solid substance contacts another solid, liquid, or gas substance, there is an attractive interaction between the particles at the 


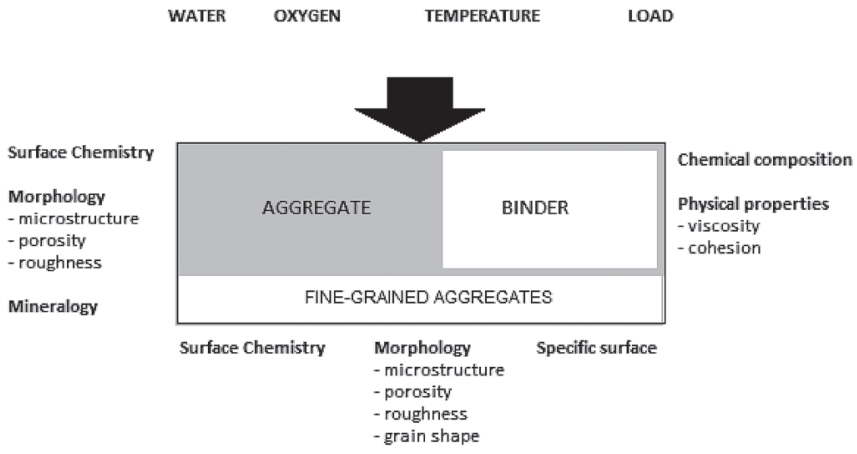

Fig. 1 Diagram of factors influencing the adhesion in asphalt mixtures (Volker at. al., 2009)

interface of the two substances. This attractive power between these two substances is called "adhesion".

An asphalt mixture consists of coarse and fine aggregates, a filler and asphalt binder. The function of the asphalt pavement surface is based on the mutual cohesion and adhesion of all the components of the asphalt mixture. The adhesion between the aggregates and asphalt binder belongs among the important factors that influence the durability of asphalt layers. The interaction between the individual components of an asphalt mixture is dependent on the factors, see Fig. 1.

There are two types of adhesion of asphalt mixtures: active and passive. Active adhesion between an asphalt binder and an aggregate occurs when the binder is able to move water from the wet surface of the aggregate. Passive adhesion is caused by external forces, e.g., increased pore pressure, and can be described as resistance to water penetrating into a system while using asphalt mixtures (Georgy, 1961).

In order to describe the bonding processes between an asphalt binder and aggregate, it is necessary to work on an adhesion theory (Nösler, 2000), (Masad at. al., 2004), which can be described by theoretical models (Volker at. al., 2009). For the most frequently used models, see Tab 1.

Tab. 1 Adhesion models between asphalt binders and aggregates considered

\begin{tabular}{|l|l|}
\hline Theory & Interaction \\
\hline Weak Boundary Layer theory & layering \\
\hline Mechanical theory & interlock \\
\hline Electrostatic theory & potential \\
\hline Chemical theory & covalent and ionic bonds \\
\hline Thermodynamic theory & surface energy \\
\hline
\end{tabular}

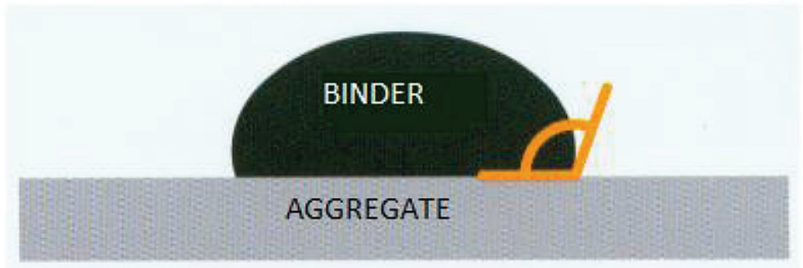

large contact angle $=$ low wettability

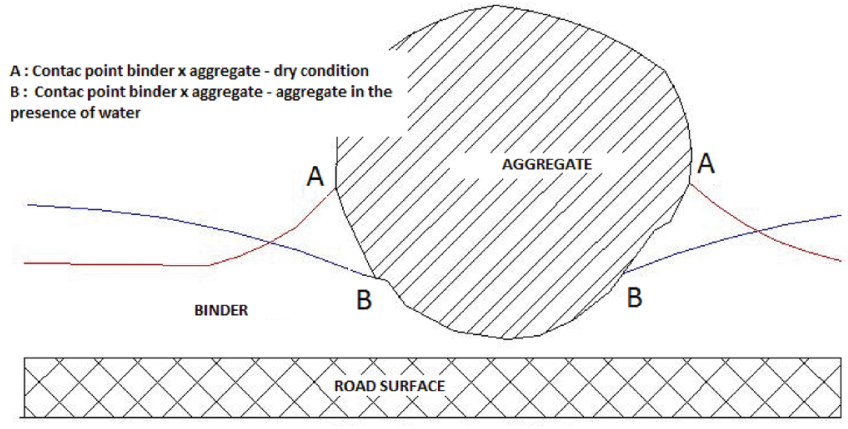

Fig. 2 Displacement of asphalt binder caused by water on the surface of the aggregates

\section{FAILURE MODELS}

The most frequently seen and common examples of adhesion models that explain adhesion failures include pore pressure, displacement (see Fig. 2), infiltration, and boundary layer damage models (Volker at. al., 2009). These models rarely exist in isolation in practice; in most cases a combination of models occurs. Being affected by water is the one thing that these models have in common, because water is the main cause of adhesion failure (Hefer at. al., 2005), since water is a bipolar liquid. The double pole has a positive and negative charge, and the chemical bonds among the atoms make an angle of approximately $105^{\circ} \mathrm{C}$. Water molecules are slightly attracted by the hydrophilic surface of the mineral (aggregate), so a saturation of the surface charges takes place. This results in a gradual displacement of a non-polar asphalt binder from the surface of the aggregates. Further minor factors include the transport loads, temperature conditions, and quality of the binder and aggregate. A marginal factor is also the thickness of the binder layer on the aggregates. In an experimental study, Mondal et al (Mondal at. al., 2012) carried out tensile tests on the interface of the aggregates and asphalt binder in order to determine the effect of the thickness of the asphalt binder on the way the damage occurred. The thickness of the asphalt film between the two polished aggregate surfaces ranged from $0.11 \mathrm{~mm}$ to $0.64 \mathrm{~mm}$. A traction load was applied at $1 \mathrm{~mm} / \mathrm{min}$, and tests were carried out at $23^{\circ} \mathrm{C}$. It was determined that the thickness of the asphalt binder does affect the adhesion and damages the bond between the aggregates and asphalt binder. With any increase in the thickness of the asphalt layer, the probability of the failure of the binder increases too.

\section{ADHESION PROMOTERS}

Adhesion promoters are chemicals that affect the interface between an organic polymer and an inorganic substrate and increase the adhesion between the two materials (Ebnesajjad, 2011). By changing the surface tension and reducing the viscosity, the asphalt binder

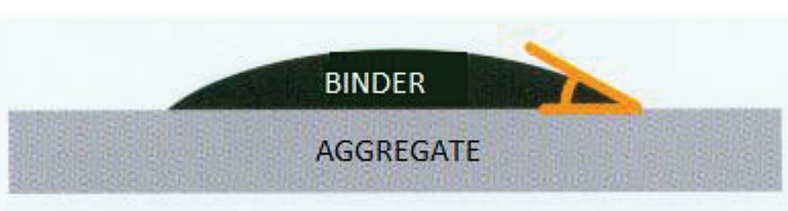

small contact angle $=$ higher wettability

Fig. 3 Contact angle of binder 
covers the surface of the aggregate better, which results in creating a strong bond (chemical bond) between the asphalt binder and aggregates, see Fig. 3.

It has been proved that silane-based adhesive additives promote the adhesion between organic and inorganic materials; furthermore, they extend their lifetime period in wet conditions (Cui at. al., 2014). The effectiveness of these promoters is attributed to the fact that they act as a chemical bridge, where one part of the molecule is attached to an aggregate and the other part is bound to the asphalt binder (Packham, 2005). There are also amine-based adhesion promoters, which consist of long hydrocarbon chains and amine functional groups. Hydrocarbon groups react with the asphalt binder and the aggregate reacts with the amine group, thereby increasing the aggregate wettability within the asphalt binder.

\section{EXPERIMENT}

The adhesion between aggregates and an asphalt binder cannot be quantified. Adhesive bonds can be assessed according to adhesion failure studies by various methods, such as chemical, mechanical, thermodynamic or electrostatic testing.

As mentioned above, the greatest effect on an asphalt binder-aggregate system is most probably water (a stripping effect). Therefore, the sensitivity or resistance of moisture to a loss of adhesion is considered to be a suitable and indirect indicator of the ability of asphalt binder to adhere to aggregates (Volker at. al., 2009).

- Testing methods for dealing with sensitivity to moisture can be divided into two categories: Tests that are carried out on coated aggregate particles, such as rotating bottle, boiling water immersion, and immersion tests.

- Tests performed on a test body, i.e., with a compacted asphalt mixture such as the Kantabro, indirect tensile stress test (ITS), or abrasion tests.

For the purpose of this article, the methodology used for determining the adhesion of asphalt binders to aggregates is in accordance with ČSN 73 6161: 2000. The determination of the adhesion of asphalt binders to aggregates, test parameters, see Tab. 2 .

The adhesion of asphalt binder to aggregates is assessed according to ČSN 736161 in the following way:

- excellent: if more than $75 \%$ of the grains of the test specimen have the characteristics of the connection of the asphalt binder film with the aggregate "A"; for the rest of the grains, the characteristics must not be less than "B" (the percentage of the coated area greater than approximately $97 \%$ );
Tab. 3 Table for assessment of adhesion

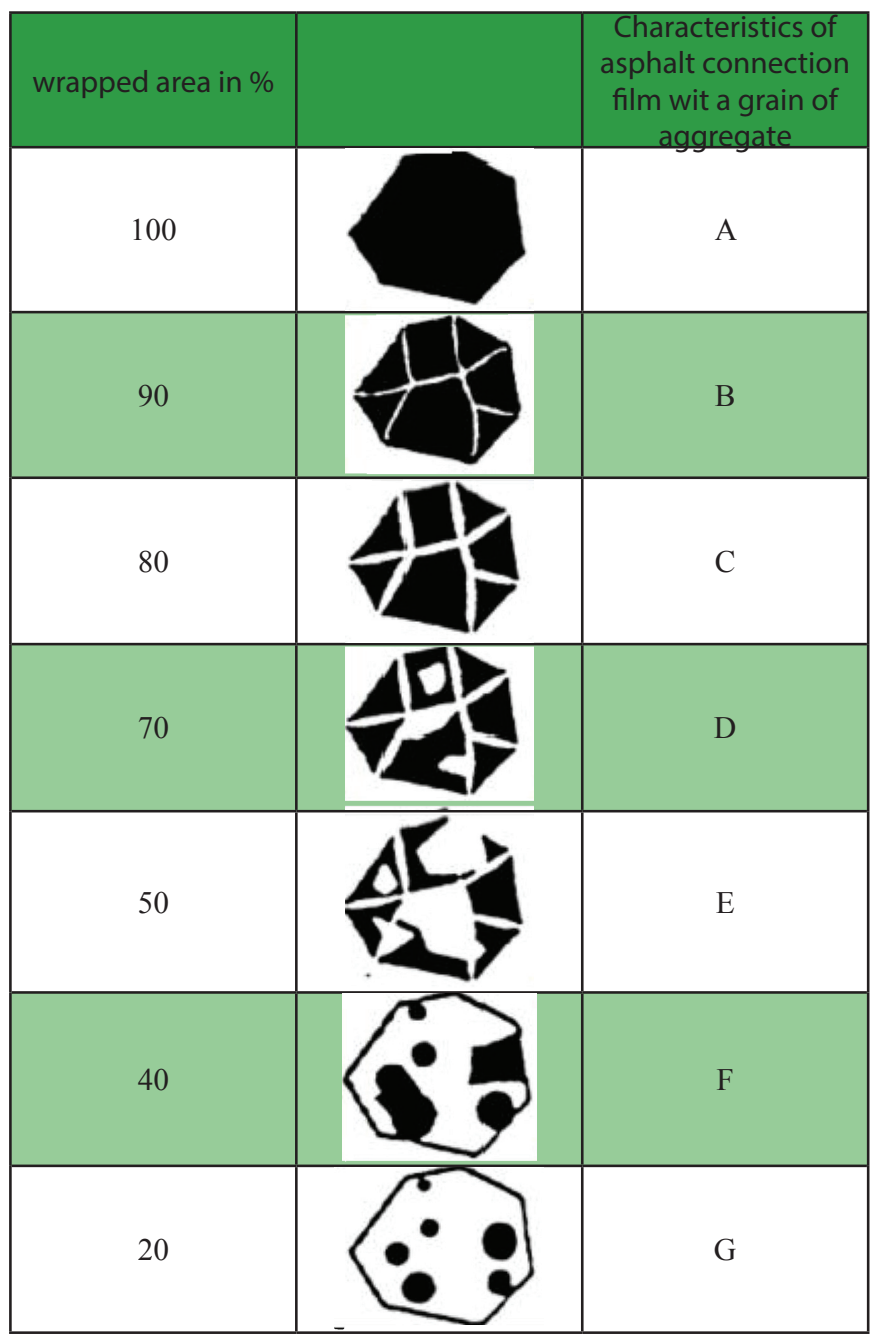

- good: if more than $75 \%$ of the grains of the test specimen have the characteristics of the connection of the asphalt binder film with the aggregate " $\mathrm{B}$ " (or better); for the rest of the grains, the characteristics must not be less than " $\mathrm{C}$ " (the percentage of the coated area greater than approximately $90 \%$ );

- pass: if more than $75 \%$ of the grains of the test specimen have the characteristics of the connection of the asphalt binder film with the aggregate "C" (or better); for the rest of the grains the characteristics must not be less than " $\mathrm{D}$ " (the percentage of the coated area greater than approximately $80 \%$ );

- not pass: If less than $75 \%$ of the grains have the characteristics "C".

Tab. 2 Parameters of ČSN 73 6161: 2000 The determination of the adhesion of asphalt binders to aggregates

\begin{tabular}{|c|c|c|c|c|c|c|}
\hline \multirow[t]{2}{*}{ Agregates } & $\begin{array}{c}\text { Number of } \\
\text { samples }\end{array}$ & $\begin{array}{c}\text { Amount of } \\
\text { binder }\end{array}$ & $\begin{array}{l}\text { Aggregate } \\
\text { fraction }\end{array}$ & $\begin{array}{c}\text { Amount } \\
\text { aggregate }\end{array}$ & $\begin{array}{c}\text { Mixing } \\
\text { temperature }\end{array}$ & $\begin{array}{c}\text { Cooling } \\
\text { time }\end{array}$ \\
\hline & 2 & $12 \pm 0.3 \mathrm{~g}$ & $8 / 16 \mathrm{~mm}$ & $300 \pm 3 \mathrm{~g}$ & variable & $24 \mathrm{~h}$ \\
\hline \multirow{2}{*}{ Water } & Kind of effect & Water temperature & Time of effect & & & \\
\hline & statically & $60 \pm 3^{\circ} \mathrm{C}$ & $60 \mathrm{~min}$ & & & \\
\hline \multirow{2}{*}{$\begin{array}{l}\text { Assessing } \\
\text { the degree of } \\
\text { wrapping }\end{array}$} & $\begin{array}{l}\text { Condition of } \\
\text { aggregate }\end{array}$ & Assessment of results & Expression of result & & & \\
\hline & wet / dry & $\begin{array}{l}\text { Visual estimate of the share of } \\
\text { the packaging with a graphic aid }\end{array}$ & $\begin{array}{c}\text { Average area of packaging } \\
\text { divided into } 4 \text { categories, } \\
\text { see Tab. } 3\end{array}$ & & & \\
\hline
\end{tabular}


Tab. 4 Parameters of the adhesive promoters

\begin{tabular}{|c|c|c|c|}
\hline Name & AD2 & Addibit & Wetfix BE \\
\hline Chemical name & Polyamides of fatty acids & $\begin{array}{c}\text { Polycondensate of tall-oil } \\
\text { acid with polyamides }\end{array}$ & $\begin{array}{c}\text { Fatty acids, tall-oil, reaction product of higher } \\
\text { carboxylic acids with diethanolamine }\end{array}$ \\
\hline State of matter & Gaseous & Liquid & Liquid \\
\hline Colour & Amber & Brown & Brown \\
\hline pH & $11\left(20^{\circ} \mathrm{C}\right)$ & $9\left(20^{\circ} \mathrm{C}\right)$ & $-20^{\circ} \mathrm{C}$ \\
\hline Melting point & $-20^{\circ} \mathrm{C}$ & $-10.5^{\circ} \mathrm{C}$ & $200^{\circ} \mathrm{C}$ \\
\hline Boiling point & $300^{\circ} \mathrm{C}$ & $160^{\circ} \mathrm{C}$ & diluted solution 11 \\
\hline
\end{tabular}

Tab. 5 Test specimens with made-up grounds

\begin{tabular}{|c|c|c|c|c|c|}
\hline & $\mathbf{5 0 / 7 0}$ & $\mathbf{5 0 / 7 0}+\mathbf{0 . 3} \%$ Addibit & $\mathbf{5 0 / 7 0}+\mathbf{0 . 3} \%$ Wetfix BE & $\mathbf{5 0 / 7 0}+\mathbf{0 . 3} \%$ AD2 & PmB 45/80-55 \\
\hline A1 8/11 & $299.8 \mathrm{~g}$ sample 1 & $300.6 \mathrm{~g}$ sample 2 & $300.2 \mathrm{~g}$ sample 3 & $300.1 \mathrm{~g}$ sample 7 & $300.2 \mathrm{~g}$ sample 10 \\
\hline $\mathbf{A 2} 8 / \mathbf{1 6}$ & $301.2 \mathrm{~g}$ sample 6 & $300.9 \mathrm{~g}$ sample 4 & $300.4 \mathrm{~g}$ sample 5 & $300.6 \mathrm{~g}$ sample 8 & $300.0 \mathrm{~g}$ sample 9 \\
\hline
\end{tabular}

\subsection{Materials}

In order to study the adhesive qualities of a new additive, the following input materials were used. There are three new promoters listed in Tab. 4, including their descriptions. Furthermore, the 50/70 road asphalt binder and polymer modified asphalt binder PmB 45/8055, A1 aggregate, and A2 aggregate were used.

\subsubsection{A1 Aggregate - 8/11}

This aggregate mainly consists of amphibolic-biotic granodiorite. Granodiorite belongs among deep acid igneous rocks with a $\mathrm{SiO}_{2}$ content higher than $65 \%$. There are plagioclases predominant over feldspar potassium. The jointing of these rocks is cuboidal or heavy-bedded. The bulk weight ranges from $2600-2800 \mathrm{~kg} / \mathrm{m}^{3}$; the Mohs hardness is $6-7$; absorption is between $0.5-2.0 \%$; and the compression strength is $120-240 \mathrm{MPa}$. Amphibole belongs among dark minerals; it forms columnar and needle-like crystals. They are perfectly fissible and parallel to the longitudinal axis of posts. The cleavage areas are approximately $60^{\circ}$ and $120^{\circ}$. Biotite (dark mica) has a hardness of $2.5-3$ and a density of $3-3.1 \mathrm{~g} / \mathrm{cm}^{3}$. It is a blackish-brown or black scaly mineral of an uneven shape with a perfect cleavability.

\subsubsection{A2 Aggregate - 8/16}

This aggregate predominantly consists of regionally metamorphosed clay shale, i.e., paragneiss. It ranks among metamorphic rocks formed by the regional conversion of sedimentary rocks. The main macroscopic minerals are quartz, feldspar, mica, and sometimes sillimanite. Subsidiary macroscopic mineral components are graphite, cordierite, and garnet. The bulk weight varies between 2650 and $2750 \mathrm{~kg} / \mathrm{m}^{3}$; the Mohs hardness is $6-7$; the absorption is in the range of $0.1-1.2 \%$; and the compressive strength of this rock is $120--250$ $\mathrm{MPa}$.
The test specimens were prepared from the above-mentioned input materials, see Tab. 5 .

\section{ASSESSMENT OF THE EXPERIMENT}

When using the AD2, Addibit, or Wetfix BE admixtures, the adhesion of all the specimens was achieved with an assessment of "good". The asphalt mixtures that include these promoters will be able to be used according to ČSN EN 13108-1 in the underlay, base, and surface courses in all classes of the traffic loads.

Specimens without adhesive promoters with the modified PMB 45/80-55 asphalt binder were assessed as suitable and may be used according to ČSN EN 13108-1 in the wear and bedding layers of pavements with III, IV, VI and CH traffic loads.

Specimens without adhesive promoters with the 50/70 road asphalt binder were assessed as unsatisfactory. This means that aggregates without promoters are not suitable for use in the construction layers of the pavements due to particular acidic rocks, which generally do not permit good adhesion, see Tab.6.

\section{CONCLUSION}

Based on the assessment of the results of the adhesion of the asphalt binder to the aggregates, it can be concluded that the new AD2 adhesive additive favourably affects the asphalt binder's adhesion. When used, it can be expected to have a beneficial effect on the durability (lifetime period) of a pavement construction, thus reducing life cycle costs (lower maintenance costs). Other findings that resulted from carrying out the experiment include:

- Moisture has adverse effects on the adhesion of asphalt mixtures. The choice of a hydrophobic aggregate or the use of chemical promoters in a binder can help minimize this particular degradation.

- Adhesion within an asphalt binder aggregate system is a result of a combination of thermodynamic, mechanical and 
Tab. 6 Results of experiment assessment according to ČSN 736161 (2000)

\begin{tabular}{|c|c|c|c|c|c|c|c|c|c|c|c|}
\hline \multirow{2}{*}{ Rank } & \multirow{2}{*}{ Sample } & \multirow{2}{*}{ Aggregate } & \multirow{2}{*}{ Binder+ Promoter } & \multicolumn{3}{|c|}{ visual evaluation, viz tab.3 } & \multicolumn{2}{c|}{ Evaluation of adhesion } \\
\cline { 5 - 12 } & & & & A & B & C & D & E & F & G & \\
\hline 1 & 7 & A1 & $50 / 70+$ AD2 & 70 & 30 & 0 & 0 & 0 & 0 & 0 & good \\
\hline 2 & 2 & A1 & $50 / 70+$ Addibit & 70 & 25 & 5 & 0 & 0 & 0 & 0 & good \\
\hline 3 & 4 & A2 & $50 / 70+$ Addibit & 55 & 40 & 5 & 0 & 0 & 0 & 0 & good \\
\hline 4 & 3 & A1 & $50 / 70+$ Wetfix BE & 35 & 60 & 5 & 0 & 0 & 0 & 0 & good \\
\hline 5 & 8 & A2 & $50 / 70+$ AD2 & 5 & 90 & 5 & 0 & 0 & 0 & 0 & good \\
\hline 6 & 5 & A2 & $50 / 70+$ Wetfix BE & 5 & 70 & 25 & 0 & 0 & 0 & 0 & good \\
\hline 7 & 9 & A2 & PmB 45/80-55 & 25 & 60 & 10 & 5 & 0 & 0 & 0 & pass \\
\hline 8 & 10 & A1 & PmB 45/80-55 & 0 & 10 & 65 & 25 & 0 & 0 & 0 & pass \\
\hline 9 & 1 & A1 & $50 / 70$ & 0 & 30 & 20 & 40 & 10 & 0 & 0 & not pass \\
\hline 10 & 6 & A2 & $50 / 70$ & 0 & 0 & 40 & 55 & 5 & 0 & 0 & not pass \\
\hline
\end{tabular}

physico-chemical mechanisms. There is no single dominant mechanism that can define adhesion.

- A loss of adhesion in an asphalt mixture is defined as a separation of the binder (fillers) from the aggregates.

- The qualities of aggregates have a more significant effect on adhesion in comparison with the qualities of a binder.

- The use of a suitable adhesive additive not only contributes to a stronger bond between a binder and aggregates, but also improves the resistance of this bond against water. 


\section{REFERENCES}

Stehlik, D., Dasek, O., Hyzl, P., Coufalik, P., Krcmova, I., Varaus, M. (2015) Pavement construction using road waste building material - from a model to reality. In: Road Materials and Pavement Design. 2015, vol. 16, pp. 314-329, ISSN 1468-0629.

Komacka, J., Remisova, E., Liu, G., Leegwater, G., Nielsen, E. (2014) Influence of reclaimed asphalt with polymer modified bitumen on properties of different asphalts for a wearing course. In: Proceedings of the 3rd International Conference on Transportation Infrastructure, 2014, pp. 179 -185, ISBN 978-1-315-757124.

Wu, S. P, Zhong, J. J, Zhu, J. Q., Wang, D. M. (2015) Influence of demolition waste used as recycled aggregate on performance of asphalt mixture. In: Road Materials and Pavement Design. 2015, vol. 14, pp. 679-688, ISSN 1468-0629.

Hamzah, M. O., Kakar, M. R., Quadri, S. A., Valentin, J. (2014) Quantification of moisture sensitivity of warm mix asphalt using image analysis technique. In: Journal of Cleaner Production, 2014, vol. 68, pp. 200-208, ISSN 0959-6526.

Volker, H., Friemel-Göttlich, B. (2009) Bestimmung des adhäsiven Potentials von Bitumen und Gesteinsoberflächen mit Hilfe der Kontaktwinkelmessmethode [online] September 2009, last update 28.07.2011 [cit. 2017-06-09]. Available from: <http://bast.opus. hbznrw.de/volltexte/2011/128/pdf/S59.pdf>.

Georgy, W. (1961) Der Baustoff Bitumen, Aufbau, Eigenschaften und Anwendung im Bauwesen. ARBIT - Schriftreihe, Heft 13: Hamburg.
Nösler, I. (2000) Beitrag zur prüftechnischen Ansprache des Haftverhaltens zwischen Mineralstoff und Bitumen, Schriftreihe des Fachzentrums Verkehr, Band 5, Shaker Verlag, Aachen.

Masad, E., Tashman, L., Little, D. N., Zbib, H. (2004) Viscoplastic modeling of asphalt mixes with the effects of anisotropy, damage and aggregate characteristics. Submitted to the Journal of Mechanics of Materials.

Hefer, A. W., Little, D. N., Lytton, R. L. (2005) A synthesis of theories and mechanisms of bitumen-aggregate adhesion including recent advances in quantifying the effects of water. AAPT.

Mondal, S., Das, A., Ghatak, A. (2012) Effect of Thickness of a Sandwiched Layer of Bitumen between Two Aggregates on the Bond Strength: An Experimental Study, In 7th RILEM International Conference on Cracking in Pavements.

Cui, S., Blackman, B. R., Kinloch A. J., Taylor, A. C. (2014) Durability of asphalt mixtures: Effect of aggregate type and adhesion promoters, International Journal of Adhesion and Adhesives, pp. 100-111.

Ebnesajjad, S. (2011) Handbook of Adhesives and Surface Preparation: Technology, Application and Manufactureing, Oxford: Elsevier Inc..

Packham, D. E. (2005) Handbook of Adhesion Second Edition, West Sussex, UK: John Wiley and Sons Ltd.

ČSN 736161 (2000) Stanoveni přilnavosti asfaltových pojiv ke kamenivu. (Determination of adhesion of asphalt binders to aggregates). Brno: ČNI, Mai 2000. 12 pp. 